\title{
Mining for Untapped Talent and Overcoming Challenges to Diversity in Higher Education: Evidence for Inclusive Academic Programs
}

\author{
Joseph M. Green ${ }^{1} \&$ Koren A. Bedeau ${ }^{2}$ \\ ${ }^{1}$ Dean University College, North Carolina Central University, Durham, North Carolina, USA \\ ${ }^{2}$ Senior Associate Provost, George Washington University, Washington, DC, USA \\ Correspondence: Joseph M. Green, Dean University College, North Carolina Central University, Durham, North \\ Carolina, USA. E-mail: Joseph.Green@nccu.edu
}

Received: July 7, $2020 \quad$ Accepted: October 10, $2020 \quad$ Online Published: November 26, 2020

doi:10.5539/hes.v10n4p131 URL: https://doi.org/10.5539/hes.v10n4p131

\begin{abstract}
The aim of this study is to examine and explore factors that impact the successful growth of student diversity at colleges and universities in the United States of America. Special emphasis is placed on America's five decade struggle since the 1970s to increase college access and success for underserved youth. The paper reviews select federal policies and collaborative efforts by higher education institutions to diversify the population of college students, toward realizing the potential of untapped talent. In addition, the authors review and examine statistics and trends in graduation rates for undergraduate students from First-Generation (FG), Underrepresented Minority (URM) and/or Low-Income (LI) backgrounds, and highlight programs at Predominantly White Institutions (PWI) that have demonstrated improvements in graduating URM undergraduate students. Likewise, the study describes initiatives that have attempted to address the graduation gap in higher education. Readers will have an opportunity to learn about the premier national program promoting diversity and academic achievement. The study closes with a discussion and evidence for continued national interest and attention to building successful academic enrichment, support, and achievement programs for students from diverse backgrounds.
\end{abstract}

Keywords: graduation success, First-Generation Students, Underrepresented Minority (URM) students, African American students, Hispanic/Latinx students, TRiO Programs, Black Indigenous and People of Color (BIPOC)

\section{Introduction}

With an eye on America's stagnating economic growth and competitiveness in the global marketplace, postsecondary education enrollment and graduation rates have consistently been a part of the national political and economic dialogue. The Spring 2020 Term Enrollment report from the National Student Clearinghouse Research Center reports consecutive declines in projections for post secondary enrollments from 2016 through 2020. Historical barriers for students from First-Generation (FG) and/or Underrepresented Minority (URM) backgrounds persist and are evident in enrollment, and graduation rates at U.S. higher education institutions. The authors recognize that Black Indigenous and People of Color (BIPOC) are not a monolith, and represent a diversity of the socio-economic backgrounds. However, K. A. Griffin's (2020) identifies six barriers to access and success that are common for some students of color:

- The noted role of teachers and counselors and gatekeepers to valuable information about college-going

- The low expectations held by teachers that may prevent them from sharing valuable information and any affect student perceptions of their abilities and potential

- The distrust in School agents among (black) parents and students

- The lack of access to counselors in under-resourced schools

- The national trend of decreased financial aid and grant offerings

- The concentration of black, poor students in low-resources schools that fail to provide adequate opportunities to learn.

While it is important to continue to address barriers to educational access in U.S. Higher Education, the following analysis identifies instances of graduation success outcomes for URM undergraduate students at select 4-year colleges and universities. This is timely because even when the number of students enrolling immediately 
into college after graduating high school was on the rise, national college and university completion rates remained stagnated. Future enrollment trends are expected to mimic national population growth with higher projections for groups from Latinx/Hispanic, and African-American backgrounds, and lower projections for the number of high school aged students (McGee, 2015). Additionally, the American Council on Education's Minorities in Higher Education Annual Status Report concurs noting that Black students are becoming an increasingly visible presence on college and university campuses (2019). Many, although not all, are not the first to enroll in or graduate college. The number of African American students in college grew $45 \%-55 \%$ between 1980 and 2020, and by the end of the twentieth century, 1.5 million black undergraduates were enrolled in higher education institutions (Griffin, 2020). Continued increases are expected for URM student enrollment. However, according to the U.S. Department of Education, students completing college with four-year degrees, continued to hover around 63.2 percent during the period of 2012-2018, only a slight increase, up from 62.7 percent for the 2011-2017 six-year-period the condition of Education Report (2019). As such, the US, once the international leader in college degrees achieved by young adults between the ages of 25-34, now ranks $12^{\text {th }}$ behind thirty-six other developed nations (Lewin 2010, College Board 2011). This landscape suggests a need for deliberate and strategic institutional action in order to improve graduation success for URM students.

Figure 1 below depicts national six-year graduation trends for students at public and private four year institutions from 2003-2013, with a $3.4 \%$ increase across all institutions from $56 \%$ to $59.4 \%$ by 2013 . According to recent reports by the Education Trust (2018) on US higher educational institutions the overall college graduation rate for White students is 62.6 percent, compared to 41.5 percent for Latinx/Hispanic, and 40.5 percent for African-American students. This means that Latinx/Hispanic and African-American undergraduate students earn bachelor's degrees from four-year institutions at rates 20 percentage points below those of their White counterparts. Another study shows that only 13 percent of young adult Latinx/Hispanics hold bachelor's degrees, compared with 39 percent for Whites, and 21 percent for African-Americans. These analyses distinguish the graduation rates for racial/ethnic groups in private versus public colleges and universities. At private institutions African-American students' have a 54.7 percent graduation rate, compared to 73.4 percent for Whites; an 18.7 percentage-point difference. Conversely, at public institutions only 43.3 percent of American-American students graduate within six years, compared with 59.5 percent of Whites -a 16.2 percentage point gap. Additionally, Carey (2010) indicates that a 30-percentage point gap exists in the graduation rate between four year students whose parents never went to college, versus students whose parents earned a bachelor's degree or more. These data illuminate the persistent deficit in college graduation degree attainment, with URM students continuing to earn degrees at much lower rates than other racial/ethnic groups in higher educational institutions.

It is important to note in all of these statistics, data for African American and other students of color combine data from all such students irrespective of their SES or whether or not they are the first in their families to attend or graduate college. The absence of such disaggregation inevitably leads to a distortion- perhaps stereotyping- of the success of students of color in higher education. In any case, one can reasonably surmise from this survey of statistics that at this critical juncture in our nation's history, bachelor's degree attainment by young adults (25-34) have plateaued, and gaps between socio-economic and racial/ethnic groups completing college continue to widen.

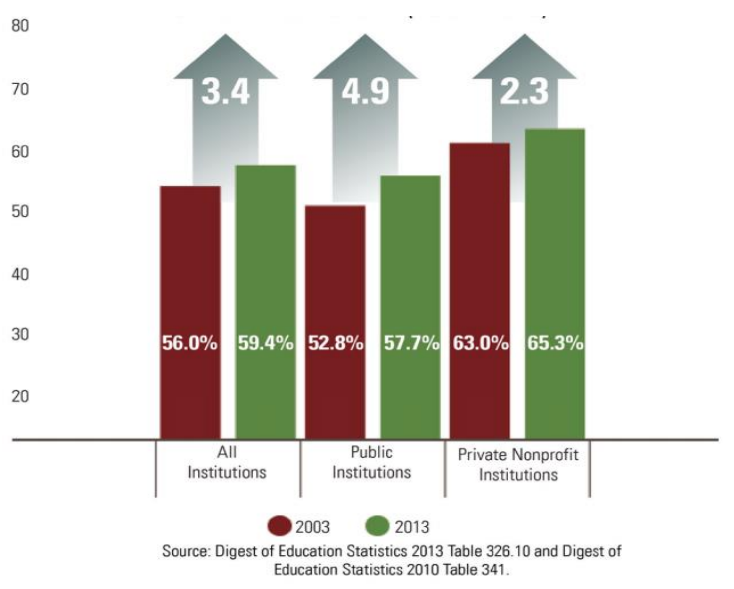

Figure 1. Change in Six-Year Graduation Rates at Four-Year Institutions (2003-2013)

Source: Rising Tide: Do College Grad Rate Gains Benefit All Students Higher Education. The Education Trust 2015. 


\section{Methodology}

The purpose of this paper is to review historical trends in access and graduation success for students who identify as Black Indegenous and People of Color (BIPOC), those who are first in their families to graduate from college and/or from low income families. The nomenclature has largely evolved from referencing Underrepresented Minorities (URM) to acknowledging individual racial/ethnic groups (for example BIPOC), however URM is the most consistent term noted when looking back over literature and data in prior decades. This is a complex topic that requires complex thinking. This effort is considering if, which and how Predominantly White Institutions (PWI) have made improvements in supporting students who are BIPOC. In other words, we have narrowed the scope of institution type to PWIs and did not examine cohorts of Historically Black Colleges and Universities (HBCU), Hispanic Serving Institutions (HSI), nor Tribal Colleges which have better graduation success with students who identify as BIPOC. Furthermore, many of the statistics combine data for students of color irrespective of socio-economic status (SES) or whether they are the first in their families to attend or graduate from college. The analysis of a significant subset of all URM students in college, is informed by the authors' insight from over 50 combined years of professional experience working in secondary/post-secondary education and higher education including service in college access and success programs - TRiO, teaching, advising, undergraduate education, undergraduate research, graduate education, and academic affairs administration. Additionally the authors have trained and worked at Historically Black Colleges and Universities and Predominantly White Institutions both Public and Private. This experience and expertise supports the understanding of the phenomenon currently under investigation.

The authors hypothesized that collaborative efforts of the Department of Education TRiO programs with colleges and universities provide a model that other universities can build upon for addressing national challenges that persist for increasing diversity in higher education, especially for students who represent the co-occurring attributes of LI, FG and URM. Explanatory case study is an appropriate method to explain causal links, and for analysis that can yield real-life context derived from both quantitative and qualitative data (Yin, 1991). The study follows an explanatory case study approach to examine how the development and implementation of post-secondary interventions at four year institutions have influenced graduation success outcomes for students from URM backgrounds. Historical data is reviewed to consider the direction of policies and climate.

The federal government commonly refers to the six-year graduation rate as a measure for student success. Likewise, universities that implement student retention initiatives and inclusive academic success programs often do so with improvements in 6-year graduation rates as a target. The Education Trust is non-profit organization that produces student focused research advocates The analysis focuses on reporting from The Education Trust and other sources examining graduation success outcomes for FG, URM and/or LI students within a six-year timeframe, and academic success programs at US higher educational institutions. The data are gathered and contextualized to understand enrollment trends and academic support programs promoting diversity in higher education. In addition, characteristics of programs are presented to identify the extent to which their objectives align with barriers to graduation success for FG, URM and/or LI and in order to comment on visible intersections between academic success programs and URM graduation rates. The study findings are limited by the inability to make generalizations, however institutional results may yield insight that is relevant beyond the particular institutions and academic support programs being discussed, and provide direction for the type of programs and policies that are best suited to leverage student talent that has historically disproportionately been excluded from higher education.

\section{Findings}

\subsection{Federal Policies \& Flagship Federal Programs Addressing Low Income, First Generation and/or URM Access to Postsecondary Education}

Integrating and diversifying student bodies at colleges and universities has been a continuous public policy objective of successive US federal government administrations, higher educational institutions, and a consortium of progressive civil society organizations, since the Civil Rights, War on Poverty, and Great Society Eras. This policy prescription was first set in motion by the landmark Brown vs. Board of Education, as well as the enactment of the 1964 Civil Rights Act which prohibited colleges and universities from discriminating based upon age, sex, race, or religion. Passage of subsequent legislative and judicial mandates intended to reify these laws have included the Higher Education Act of 1965 (which was reauthorized in 2008), and the 1973 Adams v. Richardson decision. Moreover, to administer, monitor and evaluate these legislative initiatives, the US Department of Education has offered grants, or funded programs which are embedded within public higher education institutions to enhance the recruitment, enrollment, and retention of underrepresented minorities at higher education institutions. 
According to Educator and Historian John Groutt, federal access and success programs have had a major impact on our nation. The flagship of these initiatives is the Federal TRiO program which is a series of educational opportunities to identify, recruit, and aid students from historically under resourced backgrounds. TRiO programs include: (1) Upward Bound created under the authority of the Economic Opportunity Act of 1964 which aims to prepare and increase the number of LI, FG URM high school students attending college; (2) Student Support Services (SSS) initiated with a 1968 amendment of the Higher Education Act, to increase college retention and graduation rates of URM undergraduate students by providing academic support and development (SSS projects may also provide grant aid to program participants who receive Federal Pell Grants) \& (3) The Ronald E. McNair Post Baccalaureate Achievement Program established with a 1986 Amendment of the Higher Education Act, with the objective of increasing URM acceptance to doctoral programs, and increasing $\mathrm{PhD}$ attainment rates of URMs. In 1990 Upward Bound Math and Science was established to address unique needs to prepare students in mathematics and science. Since the 1972 Amendments to the Higher Education Act, TRiO Programs have been expanded and modified to provide a broader yet more specific range of services to URM students in need of assistance selecting academic programs in higher education, and providing guidance in obtaining financial aid. Data compiled by the Department of Education and the US Census Bureau reveal that college enrollment rates across all racial/ethnic categories have steadily increased since 1972 and for three decades after. More significantly, those who classify as racial/ethnic minorities, and low income college students account for almost half of the increase. One can posit that this upward trend has been influenced by college preparation and/or academic success programs such as TRiO Programs. The US Census Bureau reports that in 2009 of the students (between the age groups 18-24 and 24-34), at four-year bachelor's degree (or above) granting institutions, Whites accounted for $74.2 \%$, Africans Americans 13.5\%, and Hispanics comprised $12.2 \%$ of the student body (Figure 2). These data also note that African-American college students grew by $25 \%$ between 1972 and 2009 (Carey 2010, Harvey, 2003). Additionally, the percentage of low-income students enrolling in college in 2009 rose to 55\%, compared to 23 percent in 1972. Despite encouraging signs in college enrollment, and while the degree-attainment rates of URM and low-income students had risen between the late 1970s and early 2000s, URM college graduates still haven't kept pace with students of other racial/ethnic groups.

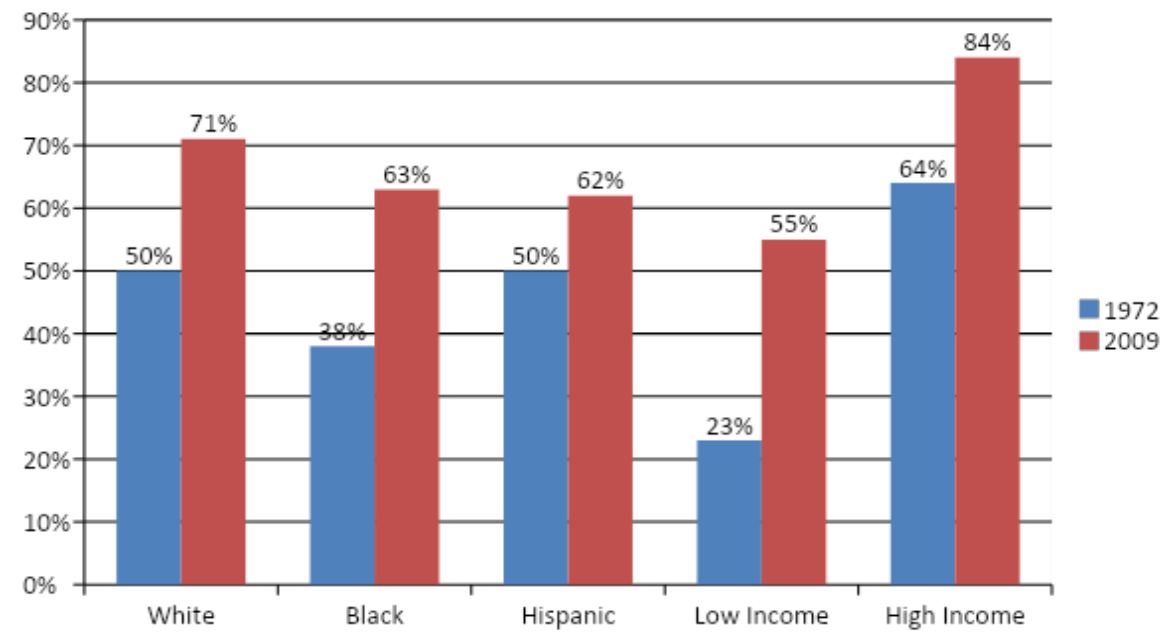

Figure 2. Percentage of high school graduates immediately enrolling in college 1972-2009

\subsection{Gaps in Degree Attainment Persists since 1970s}

According to The Education Trust, the graduation gap that separates Hispanic/Latinx and African-American students from their White counterparts, are actually wider at the time of the study than in 1975, while between low-income and high-income students it has doubled (Lynch \& Engle 2010). Disaggregating the data further by race/ethnicity unveils a more intricate portrait as $69.1 \%$ of Asian students in the $25-29$ year-old age range have earned an associate degree or higher, $48.7 \%$ of Whites, $29.4 \%$ of African-American and $19.2 \%$ of Hispanic/Latinx students have done so (College Completion Agenda 2011). Nationally, for students of color, only about 40 percent of URM students earn a bachelor's degree within six years. The figure for "nonminority" students is more than 60 percent (Lynch \& Engle 2010). As has been mentioned previously, by 2009 African-Americans were nearly $13 \%$ of total enrollments in higher education, but in the 2006-07 academic year 
they earned only $9.6 \%$ of all bachelor's degrees awarded. The very low graduation rate for URMs in higher education continues to be compelling and critical. The Education Trust points out that only two out of every five African-American students who enroll as freshmen in college go on to graduate within six years from the same institution they entered. Moreover, at nearly two-thirds of the colleges and universities they studied, fewer than half of African-American students actually obtain the bachelor's degree they sought at entry, and at one-third of the colleges fewer than 35 percent graduate (Lynch \& Engle 2010). Indeed, although access to higher education for URMs has increased over the years, these students' college success, as measured by completion and degree attainment, has not improved in considerable amounts. These numbers are truly striking as other Education Trust reports illustrate that completion rates for the Fall 2002 cohort of all 4-year institutions was merely 57 percent. Ryu (2009) also highlights that people of color received 23 percent of the total bachelor's degrees awarded in 2006 at four-year institutions, up from 19 percent 10 years earlier. Additionally, according to the Education Trust, the graduation rate for African-American students in private colleges and universities is $54.7 \%$ compared with 73.4\% for Whites-an 18.7 percentage-point gap. Similarly, at public institutions, only $43.3 \%$ of African-American students graduate within six years, compared with $59.5 \%$ of Whites-a 16.2 percentage point gap (Lynch \& Engle 2010).

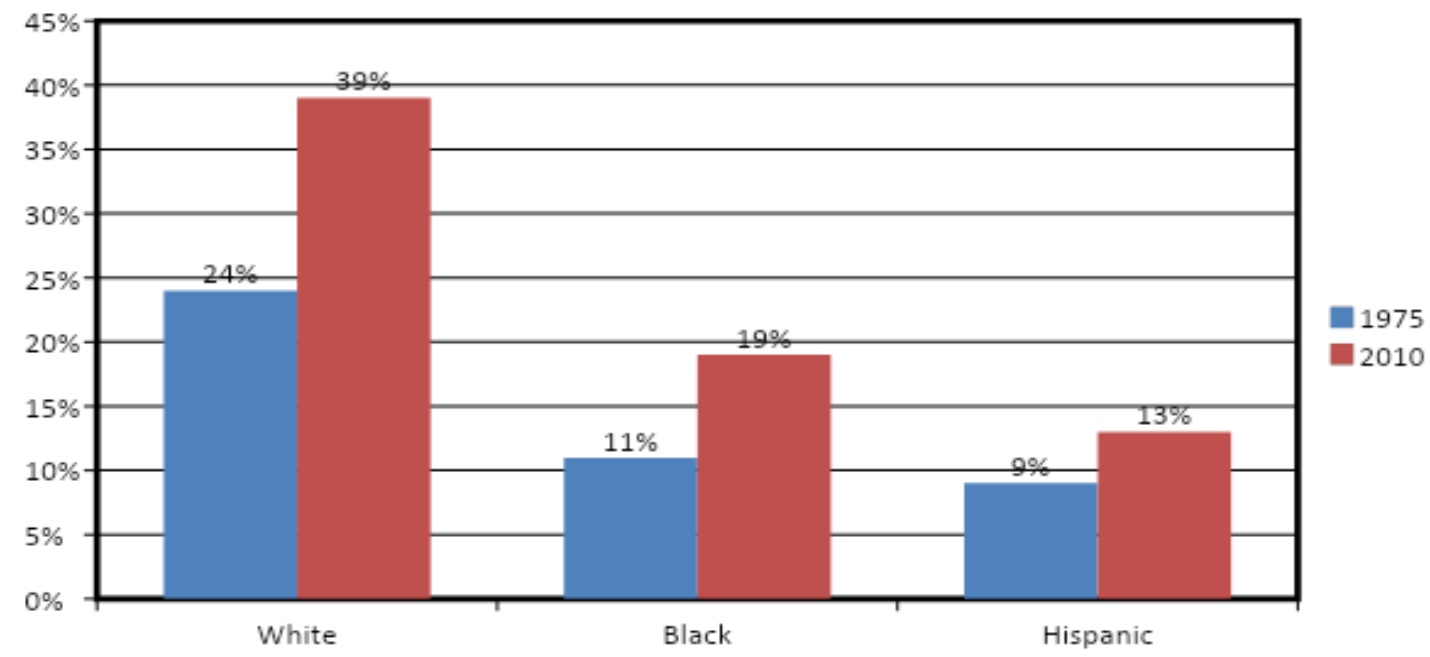

Figure 3. Degree attainment gaps have grown Bachelor's degree attainment by young adults (25-29 year olds)

Source: NCES, Condition of Education (2010) and U.S. Census Bureau, Educational Attainment in the United States: 2010

The Journal of Blacks in Higher Education and the Education Trust postulate several reasons for the lower college graduation rates of URMs as well as the large Black-White gap in college completions. Firstly, some argue that an unwelcoming or non-nurturing climate at some colleges and universities can affect the URM students' experience, their progression, and consequently their graduation prospects. If URM students do not feel a sense of belonging, or if they encounter forms of racial tensions, they are more likely to drop-out of college. Additionally, many URM students who enroll in college have not been sufficiently prepared for a rigorous college-level curriculum. When students receive inadequate training at the K-12 educational level this further hampers many URM students as they attempt to succeed in college, where a more demanding course load could lead to poor grades and frustration, increasing the likelihood that these students will drop out. Moreover, many URM students come from families which do not have a legacy of higher education participation, and thus may not receive the modelling encouragement, and understanding that is advantageous for all students' in higher education. It is unfortunate that many URMs drop out of college for financial reasons. Indeed, the Journal of Blacks in Higher Education maintains that two-thirds of African-American college students do so for this very reason as many decide they do not want to build up large debt. Other African-American students have dropped out of college because they need to enter the workforce to help support their families, and many who've tried to work while going to college find this simultaneous undertaking too strenuous, and so again many of these students will drop out of college.

Generally, although access to higher education for URMs has indeed increased over the past thirty years, students' success in college- as measured by graduation and degree attainment-has not improved at similar rates. 
As such, while inclusive URM enrollment increases remains important, institutional programs must also adjust their efforts towards shepherding URM students through the college pipeline and attaining or completing their college degrees. In other words, programs serving URM students within colleges and universities should focus on enrollment and retention, but also place emphasis and resources toward graduation of URMs students.

\subsection{Instances of Success in URM Undergraduate Student Graduation}

Several factors can influence graduation rates, including the institution's size, student population, and available resources per student (Lynch \& Engle 2010). In addition, some colleges might have made gains as a result of becoming more selective in admissions, rather than improving the academic success of their students (Carey 2010). Nonetheless, academic success programs geared to FG, URM and/or LI, students demonstrate deliberate action toward improvements in leveraging historically untapped talent. When it comes to the pursuit of improved URM degree attainment of students within these groups, some higher education institutions stand out from the rest. Georgia State University, the University of South Florida, Florida State University, The Ohio State University and the University of Oklahoma all experienced exemplary improvement between 2002 - 2007 and were included as a list of "Top Gainers" (Engle \& Theokas 2010). As previously alluded in the methodology section, a bit of caution is required in reviewing such data, however, because they only reflect graduation "success" of students at a limited cohort of higher education institutions and as compared to graduate rates inclusive of White students. They do not capture the success of such special focus institutions such as Historically Black Colleges and Universities (HBCU) for example, that have had enormous success in advancing URM students to graduation, many of whom share similar attributes as those reported in this analysis However, the academic success programs within the particular institutions included in this analysis have had impact and gained recognition because they implemented inclusive education programs that bridge the divide between White and URM student's completion of undergraduate degree programs. The Georgia State University Office of Educational Opportunity and TRiO programs facilitate a variety of programs that provide access to educational opportunities which aim to increase retention and graduation rates. As such, in 2002, only $32.3 \%$ of its minority students graduated in six years (Engle \& Theokas 2010). According to the Education Trust by 2007, that number jumped to $50.7 \%$, an increase of 18.4 percentage points. Georgia State administrators attribute this improvement in minority graduation rates to their holistic honing in on the relevant data, to identify the various potholes on the path to a bachelor's degree for GSU students. This included delineating where and why their high failure rates were in introductory courses, why there were high dropout rates between the sophomore and junior years, and when students began transitioning into their major coursework. By taking these steps GSU was able to pinpoint which programs were effective in aiding URM students.

The University of South Florida (USF) is also included on the list of "Top Gainers," coming in at number 21, with a 9.4 percentage point improvement in its 6-year graduation rate for URMs between 2002-2007 (Melendez 2010). In striving to be a leading and competitive national research institution, USF committed to not only raising undergraduate admissions standards, but also prioritizing greater diversity of its student body, and aspiring to graduate more historically underrepresented students each year. To accomplish this USF instituted several programs to support student's academic experience. Not too far away from USF is Florida State University (FSU) which makes the list at number 25 , and also has an academic success program geared toward graduation. The FSU Center for Academic Retention and Enhancement (C.A.R.E.) provides a summer bridge program before the freshman year to equip students with academic advising, college success skills, social orientation, and continues to serve as an advocate throughout degree attainment with academic coaching, tutoring, financial aid counseling, and mentorship. Ideally program participants gain needed foundational experience which enhances academic preparedness for the challenges of university. FSU C.A.R.E. has been credited with providing preparation, orientation and academic support programming for students who are among the first in their family to attend college, and for those who otherwise may face unique challenges in college because of economic, cultural or educational circumstances. FSU has been able to achieve one of the nation's highest rate/percentage of URM graduates. Ohio State University has also improved their graduation rates by an impressive 10.1 percentage points since 2002 (Engle \& Theokas 2010). The university's Todd Anthony Bell National Resource Center on the African American Male is considered an important part of the institution's strategy to improve minority graduation rates, particularly among males (Engle \& Theokas 2010). The center sponsors programs aimed at better connecting African-American males with on-campus resources such as early arrival freshmen orientation, faculty and peer mentoring, and "intrusive" advising. Ohio State officials credit this program with significantly boosting the rate at which African-American males return for their second year.

Another stand out program which made the "Top Gainers" list is Project Threshold at the University of Oklahoma. This TRiO-program is designed to serve students who are either first generation, economically 
disadvantaged or disabled. Project Threshold maintains that it provides a personalized approach to delivering academic support services to individuals who may face barriers to academic success in their college careers. Hence as student's matriculate and transition throughout their college careers, and towards the goal of graduation, Project Threshold is there every step of the way, offering academic advice, financial aid information, enrollment assistance, computer lab and tutorial services. As a result, $60 \%$ of its participants have graduated within six-years since 2005.

The federal government's six-year graduation rate is a common measure for institutional success with undergraduate students. An institution can have a relatively high graduation rate for URM students but still have large enrollment gaps because White students do even better (Lynch \& Engle 2010). The Educational Trust and its allies have undertaken the task of looking behind the numbers, to provide a profile of which public colleges and universities are realizing relatively high URM graduation rates within six years. The graduation-rate data based on Integrated Postsecondary Education Data Systems (IPEDS) surveys, demonstrates that while some institutions mimic national graduation-rate gaps between White and Black students there are some institutions, where Black students graduate at rates equal or nearly equal to the rates of their White counterparts. In 2017, URM students at the University of North Carolina at Greensboro, CUNY Queens College, and the University of Tennessee-Martin graduated at nearly the same rates than the overall undergraduate populations (See Table 1). The Education Trust report of institutions with the highest 6-year graduation rates shows that a number of public colleges and universities (including many with large enrollment of URMs) have also reported more narrow gaps in the graduation rates for URM students (when compared to their overall institutional rate).

Table 1. 2020 The Education Trust: College Results Online 2017 6-Year Grad Rate http://collegeresults.org/search1b.aspx?institutionid=199148

\begin{tabular}{lllll}
\hline Top 15 College or University & $\begin{array}{l}\text { 6-Year } \\
\text { Grad Rate }\end{array}$ & $\begin{array}{l}\text { URM 6-Year } \\
\text { Grad Rate }\end{array}$ & $\begin{array}{l}\text { \% Pell Recipients } \\
\text { Among Freshmen }\end{array}$ & \%RM \\
\hline California State University-Chico & $65.5 \%$ & $58.8 \%$ & $44.0 \%$ & $34.5 \%$ \\
Western Carolina University & $59.0 \%$ & $49.4 \%$ & $42.1 \%$ & $13.5 \%$ \\
University of North Carolina at Greensboro & $\mathbf{5 4 . 3 \%}$ & $\mathbf{5 4 . 4 \%}$ & $50.2 \%$ & $36.7 \%$ \\
CUNY Queens College & $\mathbf{5 3 . 8 \%}$ & $\mathbf{5 0 . 0 \%}$ & $50.7 \%$ & $36.4 \%$ \\
Southeast Missouri State University & $52.1 \%$ & $42.9 \%$ & $36.0 \%$ & $11.9 \%$ \\
Sam Houston State University & $51.3 \%$ & $47.5 \%$ & $48.0 \%$ & $41.4 \%$ \\
The University of Tennessee-Martin & $\mathbf{5 0 . 2 \%}$ & $\mathbf{5 1 . 1 \%}$ & $47.6 \%$ & $16.5 \%$ \\
University of Central Missouri & $49.1 \%$ & $37.7 \%$ & $39.4 \%$ & $14.7 \%$ \\
University of Nebraska at Omaha & $47.7 \%$ & $37.8 \%$ & $38.2 \%$ & $18.8 \%$ \\
Wayne State University & $46.6 \%$ & $21.4 \%$ & $43.8 \%$ & $21.5 \%$ \\
Arkansas State University- Main Campus & $46.0 \%$ & $38.6 \%$ & $40.3 \%$ & $15.2 \%$ \\
University of Louisiana at Lafayette & $44.1 \%$ & $33.1 \%$ & $38.3 \%$ & $25.3 \%$ \\
Middle Tennessee State University & $44.0 \%$ & $40.6 \%$ & $47.3 \%$ & $26.7 \%$ \\
University of Memphis & $43.2 \%$ & $30.8 \%$ & $53.4 \%$ & $40.7 \%$ \\
University of Central Arkansas & $41.1 \%$ & $28.6 \%$ & $42.6 \%$ & $22.2 \%$ \\
\hline
\end{tabular}

All of the Top 15 College/Universities (Table 1) boast Department of Education funded TRiO programs. Fourteen of the 15 universities have TRiO Student Support Services programs which specifically focus on retention and graduation. While these data do not assert correlation, one can infer that these initiatives have some impact on URM graduation rates. Consistent with past trends, overall we do not observe alignment with increases in graduation rates for non-URM populations with improvements in URM graduation rates at the Top 15 performing universities. However there are instances where the graduation rate for URM students improves and in select cases URM graduation rates are better when we review the Top 15, and Top 25 cohort of schools. California State University-Chico is a Hispanic Serving Institution (enrolling at least 25\% hispanic/latinx students). CSU-Chico is number 1 in the Top 15, with an overall graduation rate of $65.5 \%$, compared to a $58.8 \%$ graduation rate for their URM students. The results for the Top 25 6-year graduation rates, show Rutgers University-Newark is highest with a graduation rate at $67.8 \%$ for non-URM students, and their URM graduation rate was $65.2 \%$, while at SUNY at Albany (number 3 of 25) the URM student rate was higher at $70.9 \%$, than the non-URM graduate student rate was lower at $65.0 \%$. 
Table 2. 2020 The Education Trust: College Results Online 2017 Top 25 6-Year Grad Rate http://collegeresults.org/search1b.aspx?institutionid=199148

\begin{tabular}{lllll}
\hline Top 25 College or University & $\begin{array}{l}\text { 6-Year } \\
\text { Grad Rate }\end{array}$ & $\begin{array}{l}\text { URM 6-Year } \\
\text { Grad Rate }\end{array}$ & $\begin{array}{l}\text { \% Pell Recipients } \\
\text { Among Freshmen }\end{array}$ & \% URM \\
\hline Rutgers University-Newark & $67.8 \%$ & $65.2 \%$ & $54.6 \%$ & $45.3 \%$ \\
California State University-Chico & $65.5 .0 \%$ & $58.8 \%$ & $44.0 \%$ & $34.5 \%$ \\
UNC at Greensboro & $54.3 \%$ & $54.4 \%$ & $50.2 \%$ & $36.7 \%$ \\
CUNY Queens College & $53.8 \%$ & $50.0 \%$ & $50.7 \%$ & $36.4 \%$ \\
Southeast Missouri State University & $52.1 \%$ & $42.9 \%$ & $36.0 \%$ & $11.9 \%$ \\
Sam Houston State University & $51.3 \%$ & $47.5 \%$ & $48.0 \%$ & $41.4 \%$ \\
The University of Tennessee-Martin & $50.2 \%$ & $51.1 \%$ & $47.6 \%$ & $16.5 \%$ \\
University of Central Missouri & $49.1 \%$ & $37.7 \%$ & $39.4 \%$ & $14.7 \%$ \\
University of Nebraska at Omaha & $47.7 \%$ & $37.8 \%$ & $38.2 \%$ & $18.8 \%$ \\
Wayne State University & $46.6 \%$ & $21.4 \%$ & $43.8 \%$ & $21.5 \%$ \\
Arkansas State University- Main Campus & $46.0 \%$ & $38.6 \%$ & $40.3 \%$ & $15.2 \%$ \\
University of Louisiana at Lafayette & $44.1 \%$ & $33.1 \%$ & $38.3 \%$ & $25.3 \%$ \\
Middle Tennessee State University & $44.0 \%$ & $40.6 \%$ & $47.3 \%$ & $26.7 \%$ \\
University of Memphis & $43.2 \%$ & $30.8 \%$ & $53.4 \%$ & $40.7 \%$ \\
University of Central Arkansas & $41.1 \%$ & $28.6 \%$ & $42.6 \%$ & $22.2 \%$ \\
University of Southern Alabama & $39.8 \%$ & $31.9 \%$ & $36.9 \%$ & $25.5 \%$ \\
Troy University & $39.5 \%$ & $26.8 \%$ & $43.9 \%$ & $33.0 \%$ \\
University of Louisiana at Monroe & $39.5 \%$ & $34.1 \%$ & $44.8 \%$ & $26.0 \%$ \\
Jacksonville State University & $37.2 \%$ & $25.4 \%$ & $40.4 \%$ & $20.0 \%$ \\
\hline
\end{tabular}

\section{Discussion and Recommendations}

Data presented in this paper suggests incremental progress and persistent challenges for the past five-decades to improve college access and success for FG, URM, and/or LI students. A chorus of leaders from politics, business, and academia are increasingly interested in a well trained, educated and diverse workforce. In addition, higher education institutions are challenged to produce and equip graduates with higher-value and globally relevant training and competencies (Carey 2010; Hrabowski \& Suess 2010). In 2020 nearly two dozen public higher education systems (all members of the National Association of System Heads (NASH)-came together to form the Access to Success Initiative (A2S). With support from The Education Trust, these system heads have articulated two ambitious goals: (1) to increase the number of college graduates in their states and (2) to ensure that those graduates are more broadly representative of their states' high school graduates. This consortium has pledged that they intend to halve the gaps in college-going and college success that separate African-American, Latinx/Hispanic, and American-Indian students from White and Asian-American students and low-income students from more affluent students.

United States national political leaders have also taken notice: leaders like former U. S. President Barack Obama has expressed their concern, interest, and recommendations in this work (issue). One example is the American Graduation Initiative, calling for five (5) million more college graduates by the early 2020s to help the United States regain its international dominance in educational achievement. Moreover, former President Obama also emphasized that an exceptionally skilled and educated workforce is critical to the national interest. Indeed, Carnelvale, Smith \& Strohl (2010) maintain that by 2018 63\% of jobs required a postsecondary degree, and the US will potentially have a shortfall of 3 million college-educated workers. As the Educational Trust and others continue to point out, greater emphasis on increasing college degree attainment of URMs in US academia is vital, since if demographic predictions are realized, URMs will have to obtain half of the degrees necessary to lift America back to first in the world in degree attainment. For example, Hispanics (of all categories) are on track to constitute nearly one-third of the workforce by 2050. According to Lynch \& Engle (2010), they are currently the least educationally prepared to contribute and benefit from the rapidly changing and demanding economy. Underrepresented minorities must receive the advance educational training and degrees required for a changing and skills-oriented labor force, as well as the fast pace, aggressive, and rapidly converging global marketplace. In years ahead, it will be important to disaggregate data on URMs by taking into account such variables as gender, SES, and family legacy in college attendance and graduation.

National population trends with increases in Latinx/Hispanic and African American students, and national social 
and political debates about systematic exclusion of non-White citizens are challenging higher educational institutions to at least re-examine the need for inclusive education, inclusive climates and inclusive culture change with more nuanced understanding of the diversity of student backgrounds and experiences. The authors of this study recommend three (3) approaches to positively impacting retention and success for URM in all socioeconomic categories in the academy 1) Invest in establishing programs that focus on culturally relevant, growth and strength-based approaches to learning with far less focus on deficit approaches to working URM students; 2) develop and/or enhance and increase the number of living-learning communities such that are similar to the focus of TRiO SSS/McNair Programs which have enjoyed a history of success in retaining and graduating student from primarily URM backgrounds as well as FG and LI students; and 3) engaging in collaborative efforts to learn from the Nations Historically Black Colleges and Universities (HBCUs) given the more than one-hundred and fifty years of success especially in training, educating, and moulding outstanding students/scholars. Finally, these recommendations for establishing and developing a successful program designed to increase student's success outcomes should also consider the following factors mentioned in the introduction of this paper; Internal and External supports for URM student success. Colleges and Universities can greatly influence campus culture, which leads to positive outcomes by preparing institutions for a shift in student engagement approach to now focus on students from unique backgrounds by employing a success model that utilizes strengths and asset-based/models and scaffolding learning approaches to success. Likewise, the authors contend employing rigorous academic opportunities for underserved and BIPOC undergraduate students provide optimal opportunity for retention, achievement, pursuit of graduate study, and excellence, and success.

\section{References}

Anonymous. (2009). African Americans Show Solid Gains at All Academic Degree Levels. The Journal of Blacks in Higher Education, 64, 64-69.

Anonymous. (2009). College Graduation Rates: Where Black Students Do the Best and Where They Fare Poorly Compared to Their White Peers. The Journal of Blacks in Higher Education, 65-69.

Anonymous. (2009). More Than 4.5Million African Americans Now Hold a Four-Year College Degree. The Journal of Blacks in Higher Education, 37-38.

Anonymous. (2010). State Universities That Are Making the Most Progress in Improving the Graduation Rates of Minority Students. The Journal of Blacks in Higher Education, 45-46.

Answering the Call for Justice! Documentary Film Bradley Dan and Fleming Sir 2012 Washington DC.

Bland, S. (2012). The Christian Science Monitor. Retrieved from http://www.educause.edu/ero/article/reclaiming-lead-higher-education $\%$ E2\%80\%99s-future-and-implicatio ns-technology

Carey, K. (2008). Graduation Rate Watch: Making Minority Student Success a Priority. Washington, D.C.: Education Sector.

Carey, K. (2010). U.S. College Graduation Rate Stays Pretty Much Exactly the Same. Retrieved from http://chronicle.com/blogs/brainstorm/college-grad-rates-stay-exactly-the-same/29394

Carnevale, P. A., Smith, N., \& Strohl, J. (2010). Help Wanted: Projections of Jobs \& Education Requirements through 2018. Washington, D.C.: Georgetown University: Center on Education \& the Workforce.

Current Term Enrollment Estimates Spring 2020 Report, National Student Clearinghouse Research Center, Table 1. https://nscresearchcenter.org/wp-content/uploads/CTEE_Report_Spring_2020.pdf

Education Trust. (2018). National \& State Trends for Degree Attaining for Black Adults. Retrieved from https://edtrust.org/resource/national-state-trends-degree-attainment-black-adults/

Engle, J., \& Theokas, C. (2010). Top Gainers: Some Public Four-Year Colleges and Universities Make Big Improvements in Minority Graduation Rates. Washington, D.C.: The Education Trust.

Espinosa, L. L., Turk, J. M., Taylor, M., \& Chessman, H. M. (2019). Race and Ethnicity in Higher Education: Status Report. American Council on Education Washington DC.

Griffin, K. A. (2020). Institutional Barriers, Strategies, and Benefits to Increasing the Representation of Women and Men of Color in the Professoriate. Looking Beyond the Pipeline. Higher Education Handbook of Theory and Research, 35, 277-349. https://doi.org/10.1007/978-3-030-31365-4_4

Groutt, J. (2003). Commissioned by the National TRiO Clearinghouse Washington DC.

Hrabowski, F. A., \& Suess, J. (2010). November/December). Reclaiming the Lead: Higher Education's Future 
and Implications for Technology. EDUCAUSE Review.

Kelly, A. P., Schneider, M., \& Carey, K. (2010). Rising to the Challenge: Hispanic College Graduation Rates as a National Priority. American Enterprise Institute.

Lee, Jr., J. M., Kelcey, E., Menson, R., \& Rawls, A. (2011). College Completion Agenda Progress Report 2011. New York: The College Board Advocacy and Policy Center.

Lynch, M., \& \& Engle, J. (2010). Big Gaps, Small Gaps: Some Colleges and Universities Do Better than Others in Graduating African-American Students. College Results Online. Education Trust.

Nichols, A. H., \& Evans-Bell, D. (2017). Identifying Top-and Bottom Performing Institutions. Education Trust. Washington DC. Retrieved from https://edtrust.org/resource/blackstudentsuccess/

McGee, J. (2015). Breakpoint: The Changing Marketplace for Higher Education. Baltimore, MD. Johns Hopkins University Press.

Yin, R. K. (1991). Case Study Research. Design and Methods, Sage, Newbury Park.

U.S. Department of Education, National Center for Education Statistics, Integrated Postsecondary Education Data System (IPEDS). (2018). Fall Enrollment component. See Digest of Education Statistics 2018, table 326.30Retrieved from https://nces.ed.gov/fastfacts/display.asp?id=40

\section{Copyrights}

Copyright for this article is retained by the author(s), with first publication rights granted to the journal.

This is an open-access article distributed under the terms and conditions of the Creative Commons Attribution license (http://creativecommons.org/licenses/by/4.0/). 